\title{
Notes on Globalization and Identity
}

\author{
By Christina Stojanova
}

Spring 2002 Issue of KINEMA

JEFF ET PLUTO DO MONTREAL: NOTES ON GLOBALIZATION AND IDENTITY

Two films caught my attention shown at Les Rendez-vous du Cinéma Québécois in February 1999: Carole Poliquin's medium-length documentary Turbulence and François Dyotte's medium-length docu-drama Jeff et Pluto. Both were produced in 1998 by independent film companies based in Montréal and Turbulence was co-produced by the NFB. They both raise questions about globalization, marginality, nationhood and identity that are central to our cultural quotidian, and share similar immediate concerns about the particular effects of globalization on Québec society and culture. Carol Poliquin's film Turbulence explores the social and economic parameters of globalization and their ethics in the domain of economics, while Jeff et Pluto offer original observation into the psychological and sociological effects of cultural globalization.

In an attempt to answer the pressing question why the rich become richer and the poor poorer, Poliquin structures her film around the basic concept of the chaos theory: the "butterfly effect". The butterfly effect is considered the most famous example of deterministic chaos. It is named after the American mathematician and meteorologist Edward Lorenz's groundbreaking paper "Predictability: does the flip of a butterfly wing in Brazil set off a tornado in Texas?", presented in 1972. The butterfly effect is actually visualised at the beginning of the film: tiny butterfly wings are juxtaposed with ominous lighting and thundering skies, and a voice-over commentary explains the correlation between the two. This leitmotif is to reappear five times throughout the film.

Carol Poliquin's use of the butterfly effect metaphor is justified by Mitchell Waldrop's remark that "in the global stock markets millions of individual decisions to buy or not to buy can reinforce each other, creating a boom or a recession. And an economic climate can fold back to shape the very buying decisions that produced it." (1) By venturing so boldly in the hermetic domain of markets and finances, the director relies heavily on the power of the butterfly effect image which puts in context the opinion of experts she had invited to corroborate her view point. The butterfly metaphor also serves as a link, relating the accumulation of easy (or "paper") money to the growing social malaise across the globe: unemployment in Laval; exploitation in a fish plant in Dakar; polluted river in Mexico; the fate of the young female workers burned alive in a toy factory in Bangkok; the plight of homeless squatters in Paris and the underemployed in St. Petersburg.

Courtney Brown, a sociologist and scholar of mathematical applications in social sciences, describes the three fundamental characteristics of chaotic and catastrophic phenomena as "irregular periodicity; sensitivity to initial conditions and lack of probability (or unpredictability)." ${ }^{(2)}$ In his view, these three features make chaos theories a suitable methodological tool for contemporary social studies, literature, art and culture, since they represent deterministic non-linear systems and as such are inherently prone to deterministic chaos. Naturally, measuring Lyapunov's exponents ${ }^{(3)}$ of the paper economy and identifying their divergence from the initial conditions that might suddenly upset the balance of the global financial markets and thus plunge the whole world into a nightmarish chaos, is beyond the point of the film. All the director wants to do is challenge headlong the (pseudo) scientific jingoism of free-marketeers and gurus of paper economy, and expose the arrogance of their claim that globalization is actually meant to expand the wealth of the nations. In the context of the films, their cynical rhetoric reminds us of the words of Goethe's Mephisto, that true son of Chaos: "When people hear words, they gather there is a meaning"...

For a filmmaker, Carol Poliquin ventures boldly into the domain of chaos theories. Like social and cultural scientists applying these theories in their fields, she relies heavily on faith in her attempts to at least grasp, albeit never predict or control, the impending man-made disaster. And she is borrowing concepts and metaphors from chaos theories, from political economy and social anthropology with the eclectic intensity and freedom characteristic for publicity persuasion. Interviews with renowned experts like sociologist and political scientist Ricardo Petella and political economist Jim Stanford are used as important references in her argument. These learned quotes appear at critical junctions of the film as the so much needed scientific back-up. Petella, for instance, defines the nature of the expanding self-regulating market as an omnipresent 
"ideology", as "culture" and even as "the secular religion of today." In his words, the global market is hailed as the ultimate goal of humanity's long march towards progress. The very idea of protecting society against this onslaught is being rejected with equal fervour by the most zealous Globalizers who insist that "there is no such thing as society!" At one point, Petella categorically declares: "Today, the only decision makers are the financial markets." More, they are an "autonomous entity in itself". According to Jim Stanford, this entity has begun a life of its own. In his view, "paper economy overlays the real economy. [...] the financial markets have found they can make money from buying and selling paper, so much money that it dwarfs the profits that can be made through real investment."

The film offers a neatly balanced critique of the West's laissez-faire attitude towards the predatory monsters of the multi-national financial markets. This self-serving aloofness is challenged by both the extreme Right, and by the trade-unionist Left. The General Secretary of the Board of Investment in Thailand takes upon himself the role of spokesperson for non-western free-marketeers. While passionately defending free-market values, he sees the Western control of money markets as a form of neo-colonialism, an economic genocide against underdeveloped nations. He believes that the West, spoiled by the comfort of the welfare state, is unable to compete on the open market anymore since its products have ceased to be competitive. That is why Western governments, in order to preserve their dominant role, resort to ruthless manipulation of money markets and to provocation of armed conflicts.

The principal counter-argument from the left is provided by Bill Kennedy, a teacher and activist of the Ontario teacher's union. In his view, the destructive power of the financial markets is rooted in the insatiable greed of Western investors on a collective and individual basis. In their desire to make quick and easy money, they support socially irresponsible investments (like those of the Ontario Teachers' Union Pension fund). These investments, on their turn, contribute to the further impoverishment of the underdeveloped nations. Paradoxically, they also aggravate the problems of the working Ontario teachers themselves, engendering protracted and recurring strikes. Where paper money is concerned, one could t least be sure that what goes around, comes around.

Thus the image of money markets gradually emerges as a major strange attractor ${ }^{(4)}$ in Poliquin's film. According to chaos theories, a "strange attractor" is a mysterious force located outside society whose effect is unpredictable and usually devastating. A force which, according to Petella, denies the very existence of society and could not be expected to favour long term social policies in any walk of life.

The repetition of similar visual metaphors, however, of interviews with experts, over-indulging in globalization critique, as well as of episodes featuring predicaments of the victims of the global greed, gradually widens the gap between abstract theoretical thinking and its visual concretisation. The unexplained and obliviously mystifying force of the global money market foregrounds the incompatibility of chaos theories with the positive message of the film. The inclusion of various instances of spontaneous and organised resistance against global exploitation (legal strikes, protests, illegal squatting, lock-outs, and the armed struggle of the Mexican Zapatistas) further confuse the argument. It remains unclear whether the director refers to them as a solution of the problem, or as a part of it. Chaos theories insist that chaos is perennial and, once triggered, tends to follow its own uncontrollable and self-reproductive logic. In this light, the inclusion of an episode from the international meeting in Mexico of international representatives of labour movements with the Zapatistas could be interpreted as either a suggested way out of the global chaos (which I believe was the director's idea), or as a ominous warning of the spreading and uncontrollable "butterfly effect".

Unfortunately, the neat closure of the representational narrative and the resolution of its ideological tensions into a predictable call for global solidarity in response to global exploitation considerably tames the menace of pending global financial chaos and makes it seem somehow manageable and less threatening. Not unlike Spielberg's Jurassic Park, which, as cultural chaos theorist Harriett Hawkins has elegantly put it, "is as safe from the tenets of chaos theory as Crichton's literary original is from the primordial and unruly passions." ${ }^{(5)}$ Although Turbulence points fleetingly to the enemy within -- our own greed -- it leaves a naive cathartic impression that, if we all unite in a common front against the common, enemy, the victory will be ours. The unpredictable charm of the easy money, emanated by the strange attractors -- money markets -- unfortunately remains almost unscathed by the film.

Apparently, once purposefully conjured by art, the spirit of chaos now follows its own unpredictable logic 
and demands a showdown between the forces of good and evil on all levels -- collective and individual, visible and invisible. This is a battle that involves all the domains of our human experience. In that sense, the open, self-conscious narrative of Jeff et Pluto, with its irony and improvisational ruptures, expresses in a more adequate manner the tremors of the butterfly effects that are challenging identities, values and traditions across the globe, decimating smaller indigenous cultures and undermining more powerful ones.

Certainly, the push of the Americanised global culture is not news for Québec. In her article "Canadian Narrative Cinema from the Margins", Christine Ramsay writes: "American economic domination and cultural imperialism as a centrifugal force from without that ... threatens to dissolve ... [the Canadians and the Québécois, for that matter] the centred, independent and autonomous imagined community."(6)

This centrifugal force, however, has been acquiring quantitative urgency since the introduction of NAFTA ten years ago. The immediate effects of the dramatic qualitative changes of the initial economic conditions in Québec are particularly catastrophic for the survival of the Québécois identity as it creates incalculable negative feedback on individual and collective level, allowing for an infinite number of butterfly effects within and without the traditional "worlds"(7), inhabited by the citizens of Québec.

In his low-budget video film Jeff et Pluto, director François Dyotte, with amazing socio-psychological insight, examines the butterfly-generated tremors as reflected upon two fictional citizens of east-end Montréal. The film is shot as a docu-drama, and is structured as an a mega-interview with its title heroes, Jeff and Pluto. In their late teens or early twenties, the two characters are featured as typical representatives of their generation. Dyotte features Jeff and Pluto as a new type of human species who, under the influence of the strange attractor of consumerism, are sure to perpetuate its ethos. The director, who is also the diegetic interviewer, confronts his young heroes with all kinds of questions, the purpose of which is to construct both characters as subjects and objects of the globalization processes. The answers to these questions can be used to compile a manual of desires and passions, distorted by greed and delusion, and of their tragic butterfly effect on what the philosopher Karl Popper calls "first" and "second" worlds. ${ }^{(8)}$

The film opens in a Montréal park on a bright sunny morning. At a picnic table, Jeff and Pluto are comfortably having their breakfast of burger and fries, washed down with coke. In an intertitle, the director indicates the exact time of the beginning of the interview -- 9:10 am on $8^{\text {th }}$ September 1997. Three other excerpts from the park conversations, marked at 9:50 and 10:12, are included later in the film, thus creating a time and space framework rooted in the "first" world -- that of our immediate reality.

The conversation in the park is informal, a preparation for the real interview, and revolves around trifles like the food on the table, its quality and source. It however quickly turns into an argument of a more global importance: Which products are superior -- those of "Macdo", of "Burger King", of Pepsi or of Coca-Cola? In the subsequent park sequences, the discussion evolves further to cover the wise promotion wisdom of "Macdo" in using toys based on Walt Disney characters in order to promote both their and Disney's products; the fundamental role of competition for the development of big businesses like the above mentioned fast food giants. When the director, in his capacity of an interviewer and a devil's advocate, raises the question whether fast food is good for you or "junk", his interviewees seem unimpressed and patronizingly dismiss his question on the firm logical ground that such a claim is nothing but a slander. In their view, because of the stern competition amongst the fast food chains, and in accordance with the ethics of the market, these companies cannot but produce high quality products. Their beef, their pickles are the cleanest, the best!

The real interview opens on location, chosen by Jeff and Pluto themselves. It apparently represents the social space they identify with. The Montréal Jeff and Pluto inhabit is a dreary North American city. Even the picturesque rue Notre Dame in old Montréal appears dirty and dingy, just like any other street in a North American inner city. Indeed, Jeff and Pluto have selected the parking lot at the Centre Laval Shopping Mall as they take particular pride in it. "We live nearby, and there was nothing here when we were small. The place grew with us" -- boosts Jeff. "Now there is everything: Wall-Mart, Macdo, Burger, all the clothing chains have shops, and then this huge parking here...".

The director incorporates more social spaces and cultural images. On the backdrop of a huge Tommy Hilfiger billboard, Jeff and Pluto are allowed to share their opinion about youth fashion. Who is Tommy? asks the director in the intertitle. Pluto arrogantly takes the question. He is more eloquent, better educated than 
Jeff and quickly establishes himself as the spokesperson. "Tommy", he says "knows what people like to wear; he models our generation, expresses our group identity" .

Under another billboard advertising Nike running shoes and dressed in their oversized Nike T-shirts and hats, Jeff and Pluto themselves look like walking posters. They are asked to read out loud from an article claiming that Nike's unprecedented success is based on ruthless exploitation of Vietnamese workers who get only $\$ 0.25$ per hour at Nike overseas factories. Any comment? Asks the director. Our heroes are on the defensive. Too bad, murmurs Jeff compassionately, they would have been better off with more cash...But this is how the big business is..." "That changes nothing, man", Pluto adds defiantly, "That changes nothing... And what does it have to do with it all anyway?" It has, suggests the director in the intertitle "Solidarity."

The discussion gradually escalates to incorporate more important issues. Seated before the television at Pluto's place, with a huge bottle of coke and munching on fast-food delicacies, Jeff and Pluto flip through the channels. They stumble on a discussion on globalization, hosted by Pierre Bourgault, a pioneer of the Québec independence movement and currently professor at L'Université du Québec à Montréal. "The only thing one hears these days" -- Bourgault passionately argues -- "is management and economics, management and economics, everything is management and economics, and young people are unable to understand that the very espousing of this vocabulary would undermine their own future. For this chanting means only one thing: we become richer, you -- poorer, and there is no place for you, everything is taken."

Pluto's comment? Pointing his finger at the television, he angrily declares: "I hate this liberal talk. This guy has everything -- good job, big car, big house, swimming pool... He has no clue about our problems .... Butt off from your jobs and let us move in... I hate people who think they can decide for us... As he himself liked to say, we want to be masters in our own home... Let us be!"

During another routine flipping through the channels, they come across Stéphane Dion, another authority on another vital issue, that of reconciliation of Québec and Canadian national identities. Their reaction? Simply switch to an American channel.

What about Québec indigenous population in the North? Pluto replies with his usual condescension: "They should assimilate, it is not normal to live according to traditions from three, four hundred years ago. I am from native decent myself, but am fully assimilated. I am Québécois...". In a reconciliatory tone, he turns to the film crew: "In any case, let us smoke the joint of peace.... You can stop the camera if it bugs you." Jeff also lightens up: "This is typical for our generation. We drink less, but we smoke."

The episode, devoted to culture, or more specifically to cinema, is central. It lasts almost ten minutes, about one fifth of the film. Jeff's botched martial art demonstration separates the discussion of Québec cinema from that of the American. Jeff and Pluto compete in effacing Québécois culture and in praising the American. As always, Pluto is eloquent: in his view, only Methusalem has marginally passed the test. As for Denys Arcand's The Decline of the American Empire -- Jeff saw it on "télé-Québec" because his mother insisted, and was astonished and ashamed to learn that it was the most popular and widely exported Québec film.

Although the aesthetic of the film borders on sarcastic social satire in the style of This Hour Has 22 Minutes and contains self-conscious allusions to Beavis $\&$ Butthead (Jeff and Pluto like to imitate their irritating laughter), there is a strong undercurrent feeling of sympathy and understanding. Jeff and Pluto do look and behave with the self-esteem of sophisticated men of the world, but the director gradually constructs them as archetypal victims. To quote Waldrop again, "Except for the very simplest physical systems, virtually everything and everybody in the world is caught up in a vast, non-linear web of incentives and constraints and concessions. The slightest change in one place causes tremors everywhere else."(9)

In that sense, the butterfly effect in whose web Jeff and Pluto were caught was set in motion very early on and was "causing tremors" throughout their childhood and adolescence. The key to this compassionate interpretation is offered after the final credits. In front of a poster of McDonald's clown, we see the real Jeff for the first time. A sensitive young man whose aggression is a clumsy cover for his vulnerability. In a trembling voice and looking straight into the camera, he shares his most cherished childhood memory with the director-interviewer: at the age of three, the celebrated clown personally presented him with an autographed poster. And the flashback shows stone-washed images from a celebration at McDonald's, where wide-eyed and innocent young souls are being sold into perennial slavery to the consumer culture. 
The director however goes one step further: he does show compassion and understanding for his characters but also foregrounds their personality. Therefore he highlights their bigotry, misogyny and most of all -their stubborn ignorance. The strategic placement of the McDonald episode at the very end of the film is the best argument against the "victim" interpretation. All wired and nowhere to go, Jeff and Pluto can be interpreted as the ultimate self-made losers. The sophisticated means of communication are used for senseless conversations and for making some cash by what they call "home delivery of customised goods" (weed). They are well aware of the power of technology -- Jeff is even quoted in the intertitle saying (in English) that "Internet is a New Way of Life" although he only uses it to visit porno sites. They adore American culture, but can hardly speak more than a few words of English; they love American cinema and call themselves cinephiles, but have difficulty remembering a single title. The gap between their own idea of themselves and the reality of their ignorance becomes tragicomically obvious in Jeff's clumsy martial arts stunt.

The film reveals a recognisable attitude, although it is difficult to know how deeply entrenched and how widely popular it is. But Jeff et Pluto is not a sociological thesis nor a philosophical essay. Its point is to touch a nerve, and it does. Jeff and Pluto surely can be interpreted as apparitions of the worst fears of the generation of Québec intellectuals and politicians who launched the quiet revolution and the independence movement in the sixties and warned, in the words of Guy L. Côte that "nations have died ... from the moment they began to dream the dreams of others...". Jeff and Pluto are these very same people, who Côte describes as being "ashamed of their mythology, of their domestic heroes, that are quick to mimic the fads of other lands." (10)

The social and psychological insight of the director is well paired with the improvisational talent of his two young actors, Michel Simard (Jeff) and Mario Lejeune (Pluto) and the result thwarts simplistic interpretations of their characters. True, the authenticity of passion and the arrogance of opinions ring true and scary. But the film has a touch of lightness to it, an elusive elegance and tongue-in-cheek humour that make it ingeniously entertaining, and at times -- hilariously funny.

It may sound paradoxical, but the very existence of Jeff et Pluto generates some optimistic contemplations. Turbulence places Québec society and its problems in the larger perspective of world economics caught in the web of globalization, while Jeff et Pluto shows Québec from the inside and evaluates the damage, inflicted by globalization on psychological and cultural level. But while Turbulence loses its focus in the deterministic maze of theoretical concepts and metaphors, and ends up with an inevitably pessimistic account of contemporary world, Jeff et Pluto zooms in on the unpredictable and lively details of every day life in Québec. And while Turbulence sees Québec as victimised by the devastating tornado of Global greed, Jeff et Pluto is an expression of the resiliency of Québec culture, of its strength to face its own weaknesses. This very courage could generate a reverse "butterfly effect" whose tremors might redeem Québec society from its greed -- and from the spectre of globalization.

\section{Notes}

1. Mitchell Waldrop. 1992. Complexity: The emerging science at the edge of order and chaos (Penguin, London); p. 65.

2. Courtney Brown. 1995. Chaos and Catastrophe Theories from the series Quantitative Applications in the Social Sciences (Sage Publications, California), pp. 8-11.

3. Lyapunov's characteristic exponents and Fourier's analysis are considered basic tools for measuring chaos. They are named after their inventor, the Soviet mathematician N. Lyapunov.

4. Chaos theories call strange attractors magnetic basin or point of instability, serving as a source of information as well as disorder.

5. Harriett Hawkins. 1995. Strange Attractors: Literature, culture and chaos theory (Prentice Hall/ Harvester Wheatsheaf, London), p. 44.

6. Christine Ramsay. 1993. "Canadian Narrative Cinema from the Margins: "The Nation" and Masculinity 
in Goin' Down The Road", in Revue Canadienne d'études cinématographiques, Volume 2 Nos. 2-3, 1993, p. 32 .

7. Philosopher of science Karl Popper offers and interesting description of the three dimensions or domains of human experience we simultaneously inhabit. He calls them the "three worlds". Their set of co-ordinates incessantly interact in our everyday life, yet for the purposes of scientific analysis they are usually considered as separate, even mutually exclusive determinisms. According to Popper, everyone inhabits "world one", which is ruled by physical laws such as the second law of thermodynamics, and everyone will end the same way: death is everyone's strange attractor. The way we perceive death, as well as everything we encounter throughout our lives, is strictly individual, and in terms of our "world two", i.e. in terms of our subjective consciousness, made up by our personal desires, passions and memories -- both conscious and subconscious. Popper goes on to say that, in turn, "world two" is inextricably interactive with "world three" -- or the supply of scientific, religious, cultural, philosophical, political ideas and ideologies, as well as past and present works of art that are stored in and available to us (for subjective interpretation and development) in libraries, museums, newspapers, video-shops and so on. As Popper points out, the incessant interactions -- the chaotic, non-linear cascade -- of input and output, of positive and negative feedback between all these

"worlds" is historically and individually unpredictable and incalculable, allowing for an infinite number of butterfly effects. Karl Popper. 1972. Objective Knowledge: An Evolutionary Approach (Clarendon Press, Oxford), pp. 55-63.

8. Popper, ibid. 9. Mitchell Waldrop, Op. Cit., p. 65.

10. Quoted in Michael Dorland. 1998. So Close to the State/s: The Emergence of the Canadian Feature Film Policy (Toronto: University of Toronto Press), p. 123.

\section{Author Information}

Christina STOJANOVA teaches at the Department of Media Production and Studies at the University of Regina, Canada. She has contributed to Cine-bulles, KinoKultura, and the Montreal Gazette. Her publications include chapters in Berlin Culturescapes, Making it Like a Man: Canadian Masculinities, Eastern European Cinema, Traditions in World Cinema, Horror International, Alternative Europe and Cinema and Globalization. 